\title{
ELTD1 Activation Induces an Endothelial-EMT Transition to a Myofibroblast
}

\section{Phenotype}

Helen Sheldon ${ }^{1 *}$, John Alexander², Esther M. Bridges ${ }^{1}$, Lucia Moreira³, Svetlana Reilly³, Koon Hwee Ang1, Dian Wang4, Salwa Lin 1 , Syed Haider², Alison H. Banham4, Adrian L. Harris ${ }^{1 *}$

${ }^{1}$ Cancer Research UK Molecular Oncology Laboratories, Weatherall Institute of Molecular Medicine, University of Oxford, John Radcliffe Hospital, Oxford, United Kingdom; ${ }^{2}$ The Breast Cancer Now Toby Robins Research Centre, Division of Breast Cancer Research, The Institute of Cancer Research, London, United Kingdom; ${ }^{3}$ Cardiovascular Medicine, RDM John Radcliffe Hospital, Oxford, OX3 9 DU, UK; ${ }^{4}$ Nuffield Division of Clinical Laboratory Sciences, Radcliffe Department of Medicine, John Radcliffe Hospital, Headington, Oxford OX3 9DU, UK.

*Correspondance: HS, helen.sheldon@oncology.ox.ac.uk; ALH, adrian.harris@oncology.ox.ac.uk

\begin{abstract}
ELTD1 is expressed in endothelial and vascular smooth muscle cells and has a role in angiogenesis. It has been classified as an adhesion GPCR, but as yet, no ligand has been identified and its function remains unknown. To establish its role, ELTD1 was overexpressed in endothelial cells. Expression and consequently ligand independent activation of ELTD1 results in EndMT with a loss of cell-cell contact, formation of stress fibres and mature focal adhesions and an increased expression of smooth muscle actin. The effect was pro-angiogenic, increasing Matrigel network formation and endothelial sprouting. RNA-Seq analysis after the cells had undergone EndMT revealed large increases in chemokines and cytokines involved in regulating immune response. Gene set enrichment analysis of the data identified a number of pathways involved in myofibroblast biology suggesting that the endothelial cells had undergone a type II EMT. This type of EMT is involved in wound repair and is closely associated with inflammation implicating ELTD1 in these processes.
\end{abstract}

Keywords: ELTD1, EMT, pro-angiogenic, myofibroblast

\section{Introduction}

EGF, latrophilin and seven transmembrane domain-containing protein 1 (ELTD1), recently re-designated ADGRL4 (Adhesion G Protein-Coupled Receptor L4), is an orphan adhesion GPCR of the Latrophilin family. It was first identified in 2001 by Nechiporuk et. al. and was expressed in cardiomyocytes and smooth muscles during heart development[1]. ELTD1 has a long extracellular N-terminus containing epidermal growth factor (EGF) and calcium-binding EGF domains, these domains are found in other adhesion GPCRs where they mediate cell-cell interactions and cell migration[2]. The extracellular region of ELTD1 also contains a membrane proximal GAIN (GPCR-Autoproteolysis INducing) domain which undergoes autocatalytic processing at a GPCR-proteolytic site (GPS) to give rise to an extracellular domain that is non-covalently bound at the cell surface[3].

Several members of the adhesion GPCR family have been implicated in angiogenesis. GPR124 is highly expressed in the endothelium of the central nervous system (CNS) and is essential for regulating CNS angiogenesis[4]. CD97 stimulates angiogenesis by binding to integrin on endothelial cells[5] and loss of Gpr116 in mice has also been reported to result in a subtle vascular phenotype[6]. ELTD1 expression was identified in normal vasculature[7] and 
tumour vasculature[8]. We later confirmed this finding by showing greater protein expression in tumour vasculature compared to matched normal tissues in a number of tumour types[8]. ELTD1 has also been reported to be up-regulated in glioblastoma cells as well as vasculature $[9,10]$. ELTD1 expression is regulated by VEGF[8] and in vitro and zebrafish studies identified ELTD1 as a key regulator of sprouting angiogenesis. More importantly, the growth of human ovarian and colorectal tumour xenografts were substantially inhibited using anti-mouse Eltd1 silencing[8], suggesting ELTD1 is a potential target for anti-angiogeneic therapy.

Adhesion GPCRs are a relatively new GPCR subfamily and there is limited information on their functions, especially since most have no known ligands[11]. Increased expression of GPCRs has been successfully used to help deorphanize receptors and characterise their signalling pathways[12]. In the absence of a ligand for ELTD1 we utilised this approach to help establish its role in endothelial cells.

\section{Results.}

\subsection{Expression of coELTD1 in endothelial cells}

Expression of coELTD1 was used to activate the receptor in the absence of a ligand by increasing the proportion of receptors in the active conformation[13]. Approximately 5 days after infection with a coELTD1 expressing lentivirus, both cell types underwent a form of EndMT, exhibiting an elongated spindle-like morphology (Figure 1A and Control Video S1 Control and Video S2 ELTD1). The cells lost intercellular contacts at VE-Cadherin junctions (Figure 1C) and had an increased expression of alpha smooth muscle actin ( $\alpha$ SMA), which is a mesenchymal marker of EMT[14], and a decrease in endothelial CD34 expression when compared to infected controls (Figure 1B and 1D). coELTD1 expression was confirmed in the stable human microvascular endothelial cell line HMEC-1 and in human umbilical vein endothelial cells (HUVEC) by Western blotting (Figure 2A and 2B). Expression of coELTD1 reduced cell growth in both cell types by approximately 25\% (Figure 2A and 2B) but increased angiogenic activity as evidenced by increased Matrigel $^{\mathrm{TM}}$ network formation (Figure 2C and 2D) and increased sprouting of HMEC-1 cells (Figure 2E). The sprouting assay was attempted using coELTD1 expressing HUVEC but the cells were unable to form spheroids. 
A
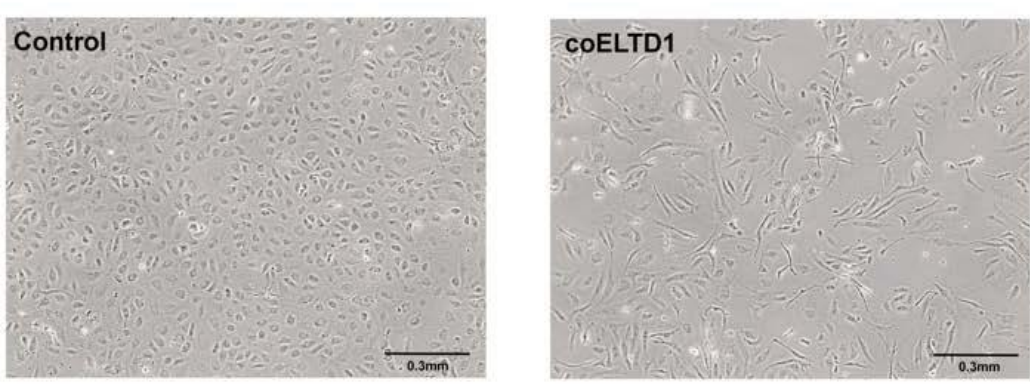

B

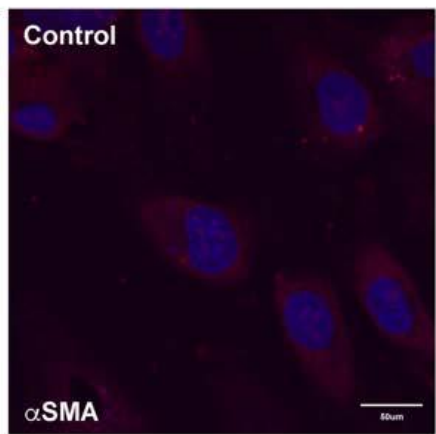

C
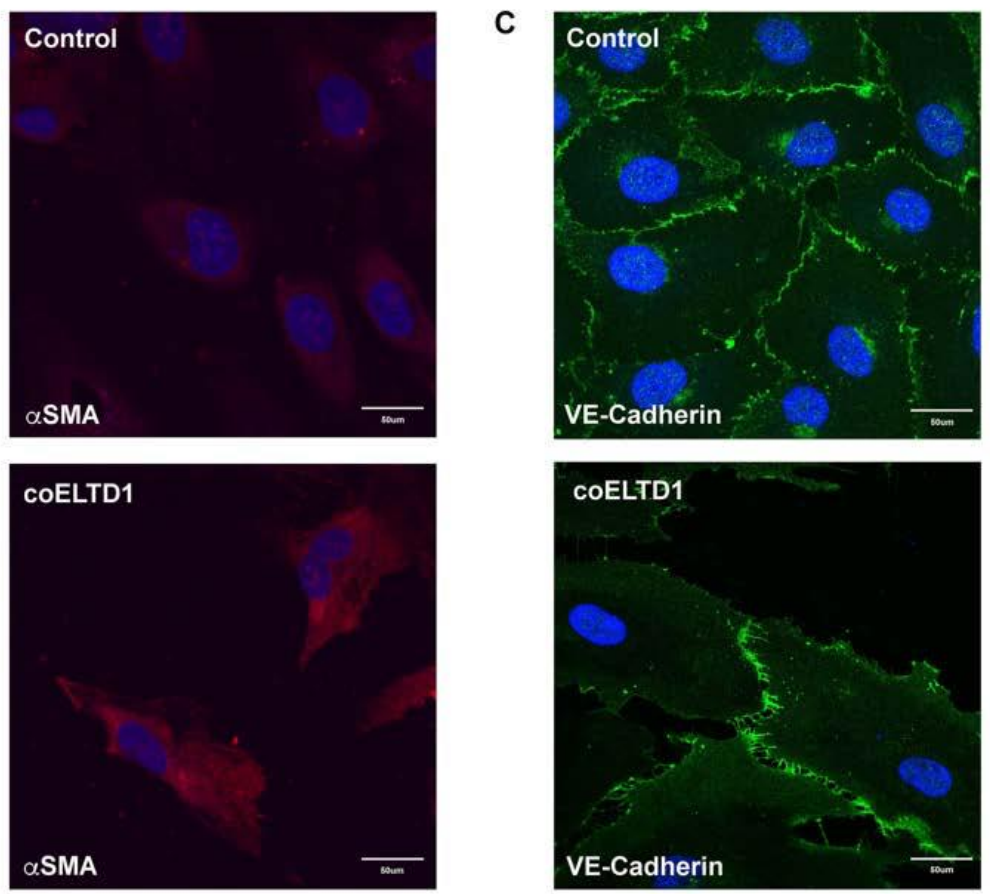

D
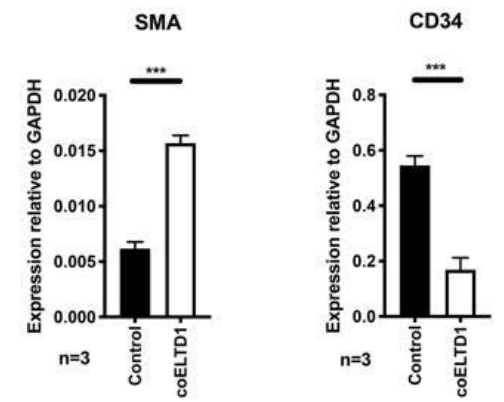

Figure 1: coELTD1 expression induces EndMT. (A) Visualization of HUVEC 120hrs post infection with control and coELTD1 expressing lentivirus. Images were taken on an AMG Evos XL Core digital microscope (Fisher Scientific) at 10x magnification. (B) Fluorescent staining of $\alpha$ SMA in control and coELTD1 expressing HUVEC cells at $120 \mathrm{hrs}$. (C) Fluorescent staining of VE-Cadherin in control and coELTD1 expressing HUVEC cells at 120hrs. Images were taken on a Zeiss LSM 880 Confocal Microscope (Zeiss) at x63 magnification. (D) QPCR of $\alpha S M A$ and CD34 in control and coELTD1 expressing HUVEC. 
A

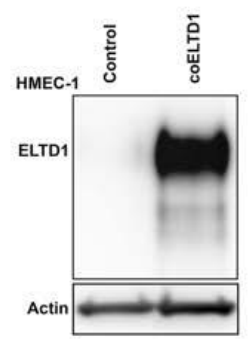

C

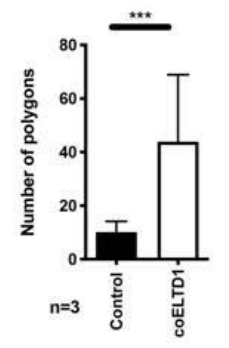

E

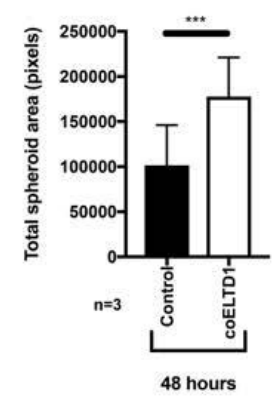

HMEC-1

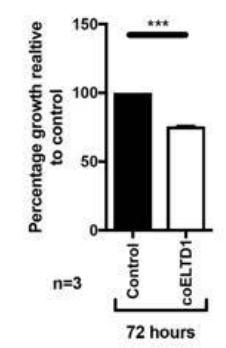

HMEC-1

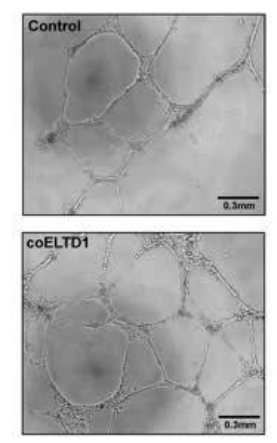

B

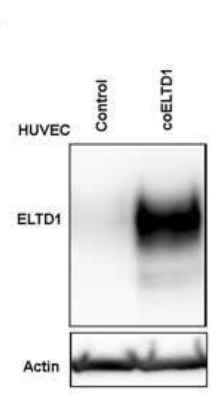

D

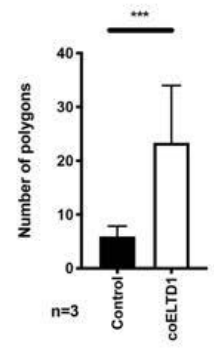

HUVEC

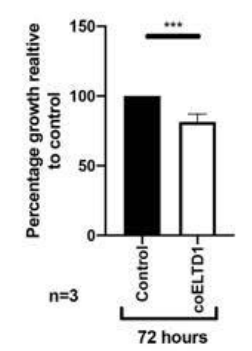

HUVEC

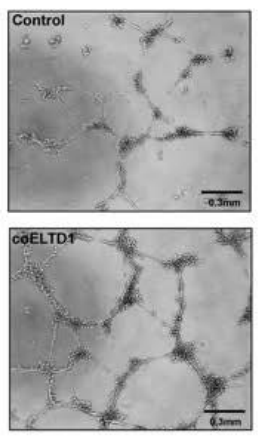

HMEC-1
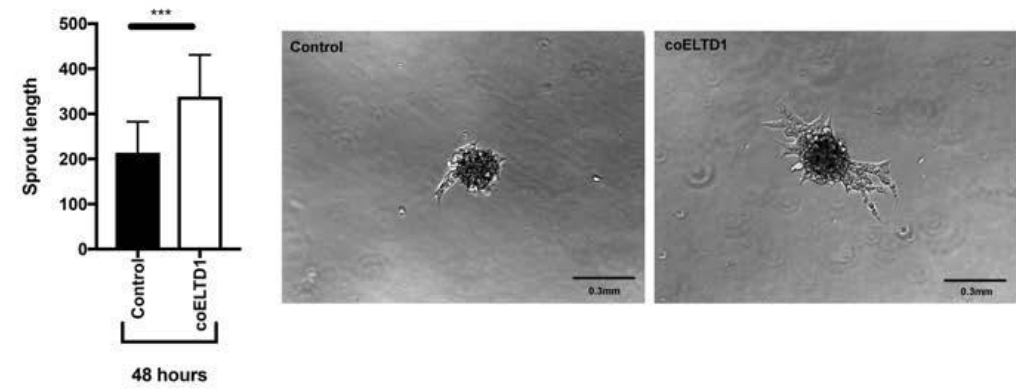

Figure 2: coELTD1 expression is pro-angiogenic. (A) Western blot of coELTD1 expression in HMEC-1 and effect of expression on proliferation. (B) Western blot of coELTD1 expression in HUVEC and effect of expression on HUVEC proliferation. (C) Matrigel assay on coELTD1 expressing HMEC-1 with quantification of polygon formation. (D) Matrigel assay on coELTD1 expressing HUVEC with quantification of polygon formation. (E) Sprouting assay in Matrige ${ }^{\mathrm{TM}}$ of coELTD1 expressing HMEC-1 with quantification of spheroid area and sprout length. Images were taken on an AMG Evos XL Core digital microscope (Fisher Scientific) at 10x magnification. 
Cell-cell adhesion assays were performed on HMEC-1 where coELTD1 expression reduced the cells ability to adhere to each other by 60\% (Figure S1C) but coELTD1 expression did not affect adhesion to several extracellular matrix proteins (Figure S1D). Both cell lines migrated but coELTD1 expression reduced migration slightly but significantly (Figure S1A and S1B).

\subsection{Expression of Tagged coELTD1}

The commercially available anti-ELTD1 antibodies did not work well for immunofluorescence and we had not yet developed in-house antibodies, therefore we tagged the extracellular domain (ECD) with HA. HA-tagging did not affect the processing and glycosylation of the ECD as an antibody raised against the ECD of ELTD1 and the HA-Tag antibody gave the same two bands described previously by our laboratory which correspond to the two glycosylated forms of the ECD[8] (Figure S2A). The increased expression of ELTD1 and HA-tagging did not appear to interfere with protein localisation as immunofluorescent staining of HUVEC cells using an anti-ELTD1 antibody against the ECD gives a similar pattern in control, coELTD1 and HA-tagged coELTD1 expressing cells (Figure S3B).

HUVEC cells expressing HA-tagged coELTD1 had the same phenotype as untagged coELTD1 with an increased network formation on Matrigel ${ }^{\mathrm{TM}}$ (Figure S2B and S2C). HA-tagged coELTD1 expressing HUVEC also had a loss of cellcell contact with HA-tagged coELTD1 localised on stretch points between detached cells anchored by VE-cadherin (Figure S2D).

\subsection{Confocal microscopy of coELTD1 induced shape changes}

coELTD1 expressing HUVECs adopt a myofibroblast-like phenotype. Myofibroblasts are characterised not only by expression of $\alpha$ SMA but also by the formation of stress fibres and large focal adhesions which enable to cells to contract and close wounds during healing[15]. coELTD1 expressing cells were stained with TRITC-phalloidin to visualise actin and paxillin to locate the focal adhesions. coELTD1 expression increased the size of the cells and re-organised the actin into stress fibres with large focal adhesions confirming myofibroblast formation (Figure 3A).

Live microscopy was performed on HA-tagged coELTD1 expressing HUVEC 10 minutes after the addition of an Alexa Fluor $488^{\circledR}$ tagged HA antibody (HA-tagged coELTD1 Video S3 and Figure 3B). HA-tagged coELTD1 was present at the cell membrane and accumulates at points of cell-cell contact when the cells begin to detach. It was also left on cell tracks as the cells migrated, suggesting a strong adhesion to the tissue culture plate surface. Higher magnification of this phenomenon showed extensive ELTD1 positive membrane deposition with circular macroaggregates present, that are thought to be integrin rich[16] (Figure 3C). The mechanism for production of these circular structures is unknown, but suggest vesicle production.

Myofibroblasts secrete extracellular matrix proteins (ECM) such as collagens, glycoproteins, proteoglycans and elastins to provide structure, cell guidance and a reservoir of growth factors during wound repair[17]. Collagen secretion was quantified and found to be significantly higher in the supernatant of coELTD1 and HA-tagged coELTD1 expressing cells (Figure 3D). 
A
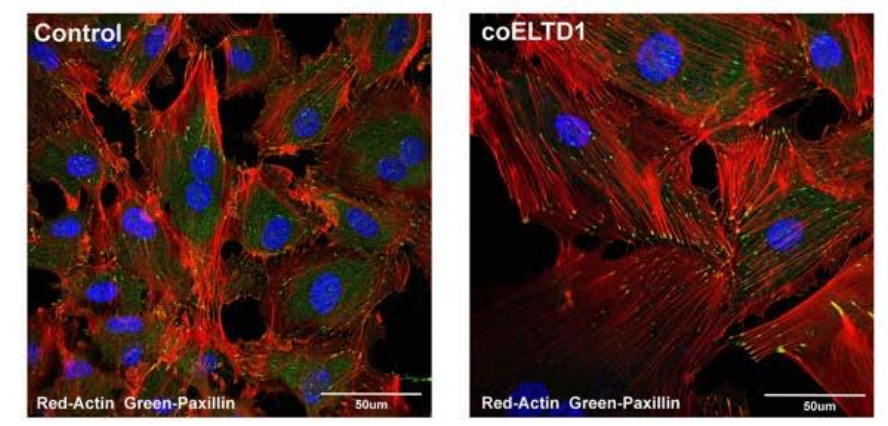

B
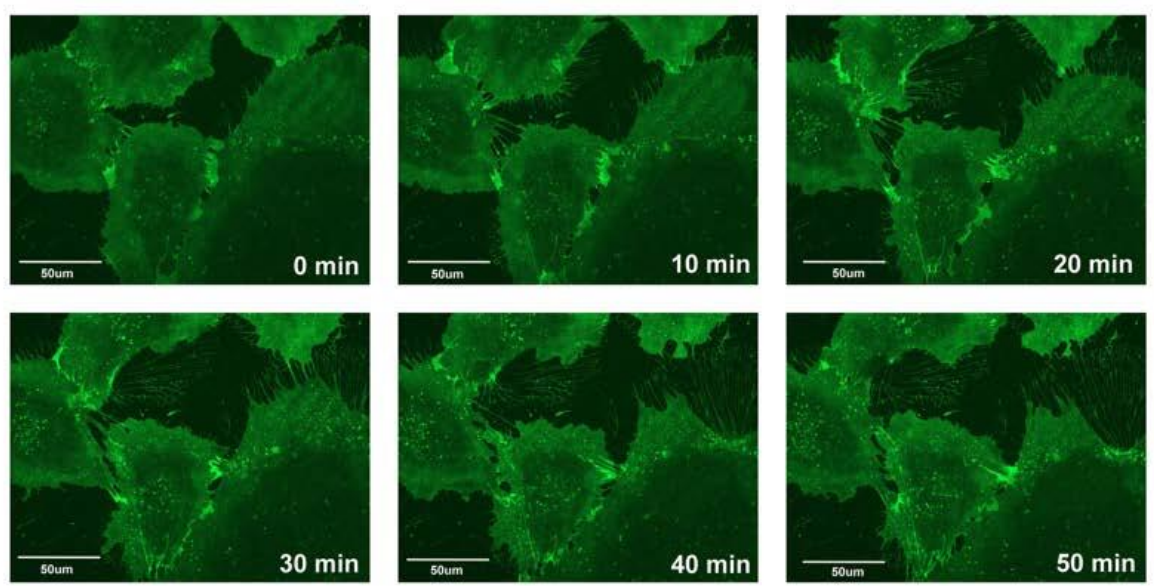

C

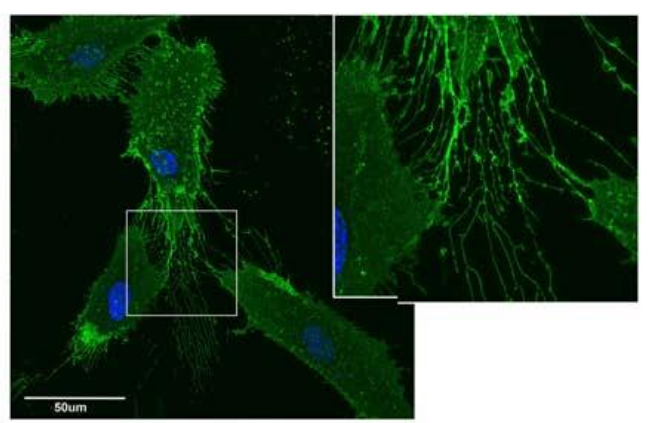

D

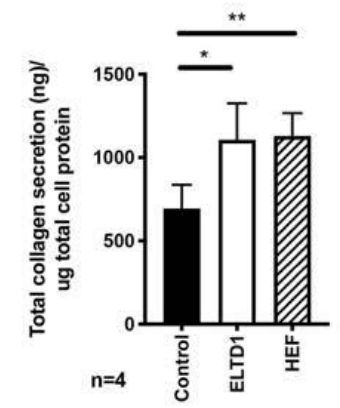

Figure 3: coELTD1 expression induces myofibroblast-like shape changes. (A) Fluorescent staining of actin (phalloidin) and paxillin in control and coELTD1 expressing HUVEC. Images were taken on a Zeiss LSM 880 Confocal Microscope (Zeiss) at x40 magnification. (B) Still images taken from HA-tagged coELTD1 Video 3 at 10 minute intervals. HUVEC cells were infected with HA-tagged coELTD1 and imaged 10 minutes after addition of HA-Alexa Fluor 488 using a Zeiss Observer spinning disc confocal microscope. (C) Membrane staining of nonpermeabilized HUVEC cells expressing HA-tagged coELTD1 using anti-HA-Alexa Fluor 488 with zoomed inset of cell tracks. Images were taken on a Zeiss LSM 880 Confocal Microscope (Zeiss) at x63 magnification. (D) Collagen assay performed on supernatant collected from HUVEC cells $120 \mathrm{hrs}$ after infection with control or coELTD1 virus. 


\subsection{RNA-Seq of coELTD1 mRNA expression profiles.}

RNA-Seq was performed after coELTD1 expression (48hrs) and after EndMT had occurred (120hrs). Comparative transcriptomics at $48 \mathrm{hrs}$ revealed 836 significantly differentially expressed genes (Top 50 most significant upregulated and down-regulated genes shown in Figure 4A and Table S2 contains full list ranked by fold change) and 683 significantly differentially expressed genes at 120hrs (Figure 4B and Table S3). Of these genes, 484 were regulated at both $48 \mathrm{hrs}$ and $120 \mathrm{hrs}$ suggesting their importance in initiation and maintenance of the EndMT phenotype (Table S4). Validation of the gene changes by QPCR was performed on the 48hrs and 120hrs samples (Figure S4B and S4C). To characterise the genes which change differently at $120 \mathrm{hrs}$ and $48 \mathrm{hrs}$, gene set enrichment analysis (GSEA) using the REACTOME pathway database was performed. GSEA revealed a significant downregulation (at 120hrs) of pathways involved in RNA metabolism, cell cycle, DNA replication and translation which is consistent with the decrease in proliferation seen in the coELTD1 expressing cells. Consistent with an endothelial-myofibroblast transition there was an upregulation in many pathways associated with myofibroblast biology such as ECM organisation and integrin interactions, collagen formation and glycosaminoglycan and heparin sulphate metabolism (Figure 4C). 
A
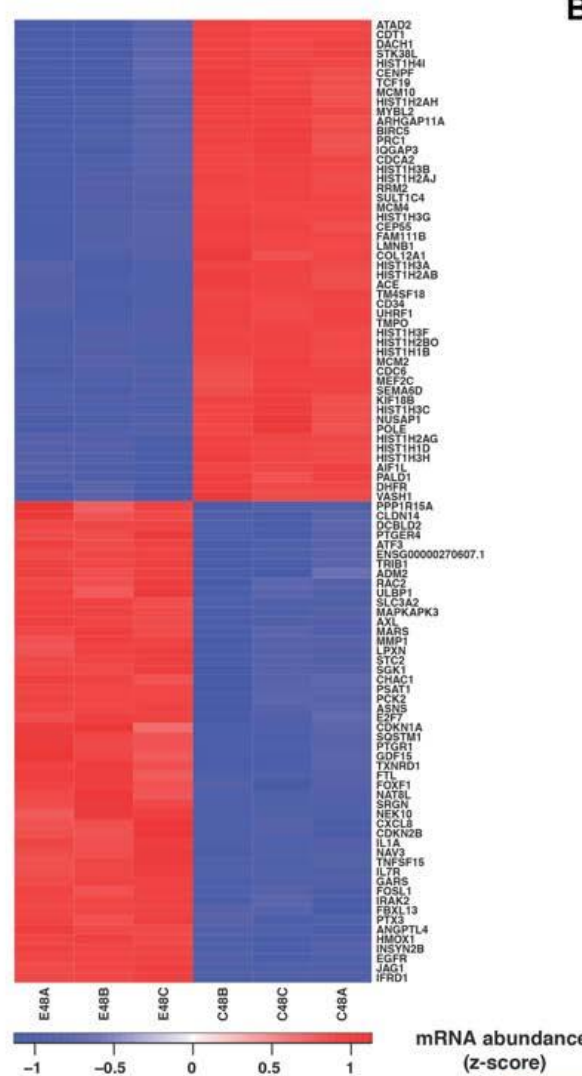

-score)
B

C

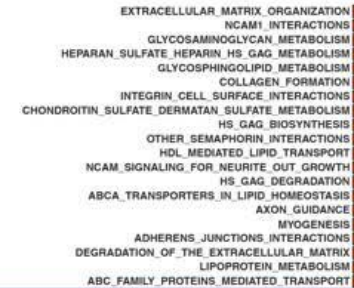

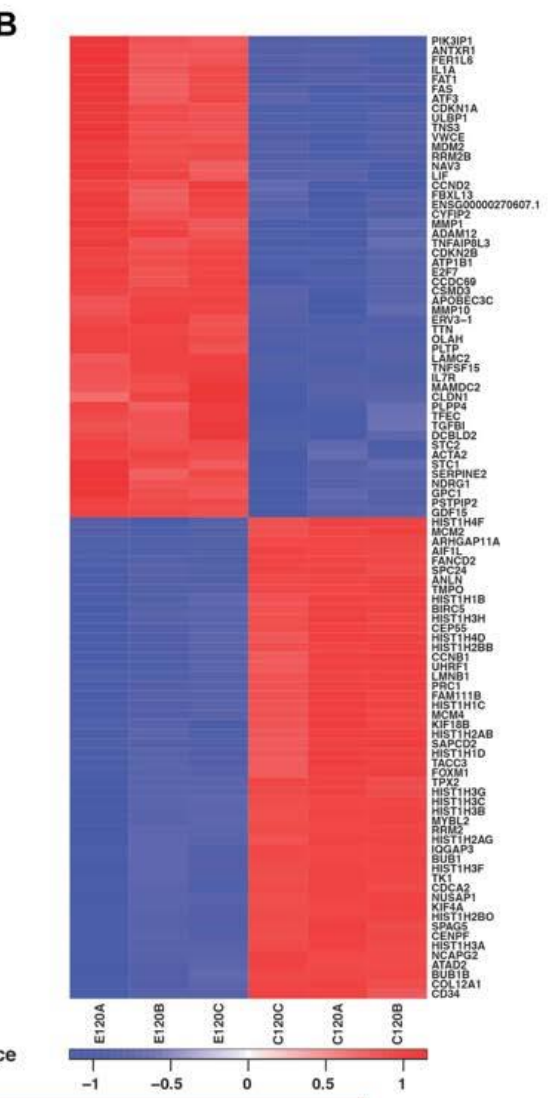

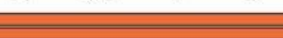

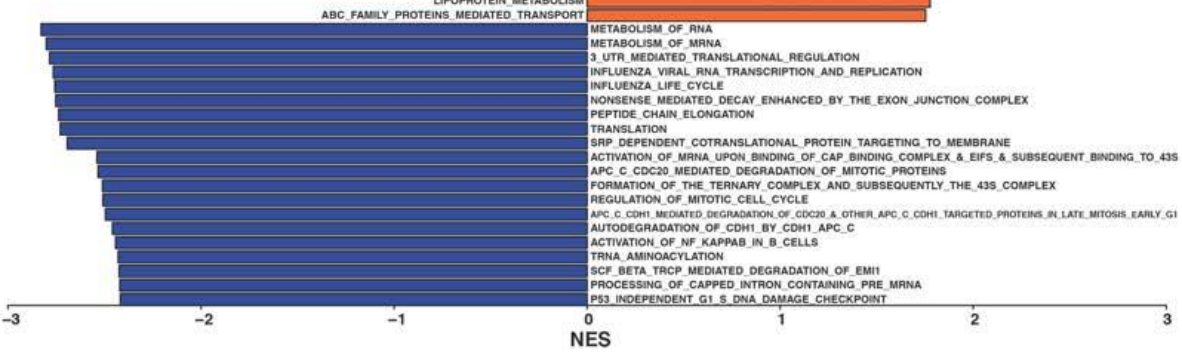

Figure 4: RNA-Seq analysis of coELTD1 expressing HUVEC. (A) Differential gene expression of top 50 upregulated genes and downregulated genes at $48 \mathrm{hrs}\left(\left|\log _{2} \mathrm{FC}\right|>1\right.$ and FDR adjusted $\mathrm{P}$ value $<0.05$ ). (B) Differential gene expression of top 50 upregulated genes and downregulated genes at $120 \mathrm{hrs}\left(\left|\log _{2} \mathrm{FC}\right|>1\right.$ and FDR adjusted $\mathrm{P}$ value $\left.<0.05\right)$. (C) Gene set enrichment analysis: Pre-ranked gene set enrichment analysis was performed using fgsea $\mathrm{R}$ package (v1.8.0) with REACTOME gene sets downloaded from MSig database ${ }^{76}$. Genes were ranked using: $\operatorname{sgn}\left(\log _{2} \mathrm{FC}\right) \mathrm{x}-\log _{10} \mathrm{P}$. For our analysis, we applied a minimum gene set size of 10 genes and performed the analysis using 500 permutations. 


\subsection{Factors effecting EndMT to myofibroblasts.}

An angiogenesis array was carried out on HUVEC supernatant collected 7 days post infection to detect released factors. Five proteins were increased in the supernatant, HB-EGF, Angiogenin, uPA, IL8 and PGF and two were decreased, PAI1 and IGFBP-2 (Figure 5A and quantification in 5B), IL1 $\alpha$ was not present on this array. RNA expression of IL8, $u P A$, IGFBP-2 and HB-EGF correlated with these changes. However, PGF expression was not significantly altered and PAI-1 expression decreased suggesting a different mechanism of regulation (Figure 5B).

A number of pathways have been implicated in the activation of EMT. TGFB1 signalling has been the most intensively studied but other pathways such as IL6, IL8, FGF, Wnt, Notch, TNF and IL1 can promote a mesenchymal phenotype in a number of cell types[18, 19]. Two of these, IL8 and IL1 $\alpha$ were highly expressed at RNA level in coELTD1 cells at 48 and 120hrs. An ELISA on HUVEC supernatants confirmed an increase in the secretion of these two factors in coELTD1 expressing cells (Figure 5C). IL1 $\alpha$, IL8 and TGFB1 were added to endothelial cells but only IL1 $\alpha$ could elicit the cell shape changes seen with coELTD1 expression (Figure 5E). IL1 $\alpha$ also increased endothelial sprouting, stress fibre formation and loss of cell-cell contact as seen with coELTD1 expression (Figure S5A and S5B). It also increased ELTD1 expression when treated for 72hrs (Figure S5C and S5D). To establish whether IL1 $\alpha$ is solely responsible for the EndMT, IL1 receptor antagonist (IL1RA) was added to inhibit this pathway. IL1RA inhibited the expression of genes known to be regulated by IL1 $\alpha$ (CSF2 and LIF) however it did not inhibit EndMT induced by coELTD1 expression (Figure 5D and 5E). Certain genes were partially inhibited by IL1RA (STC1, STC2 and NAT8L) suggesting co-operation between ELTD1 and IL1 $\alpha$ induced pathways. Other genes were unaffected and may represent ELTD1 direct targets such as HMOX1, JUN and RAB11FIP4 (Figure 5D). 
A

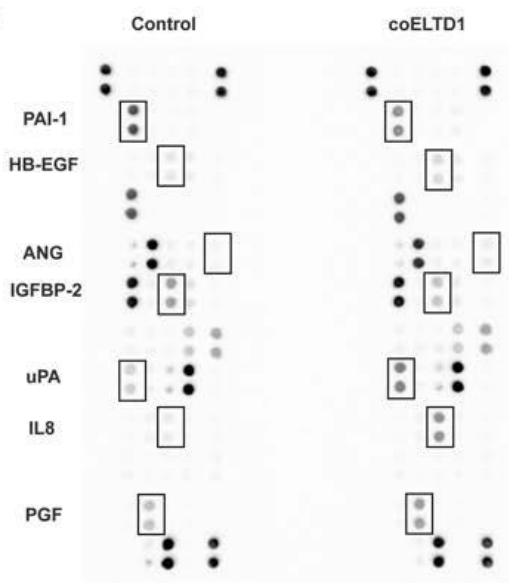

C

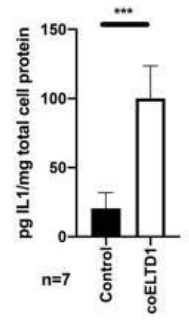

E
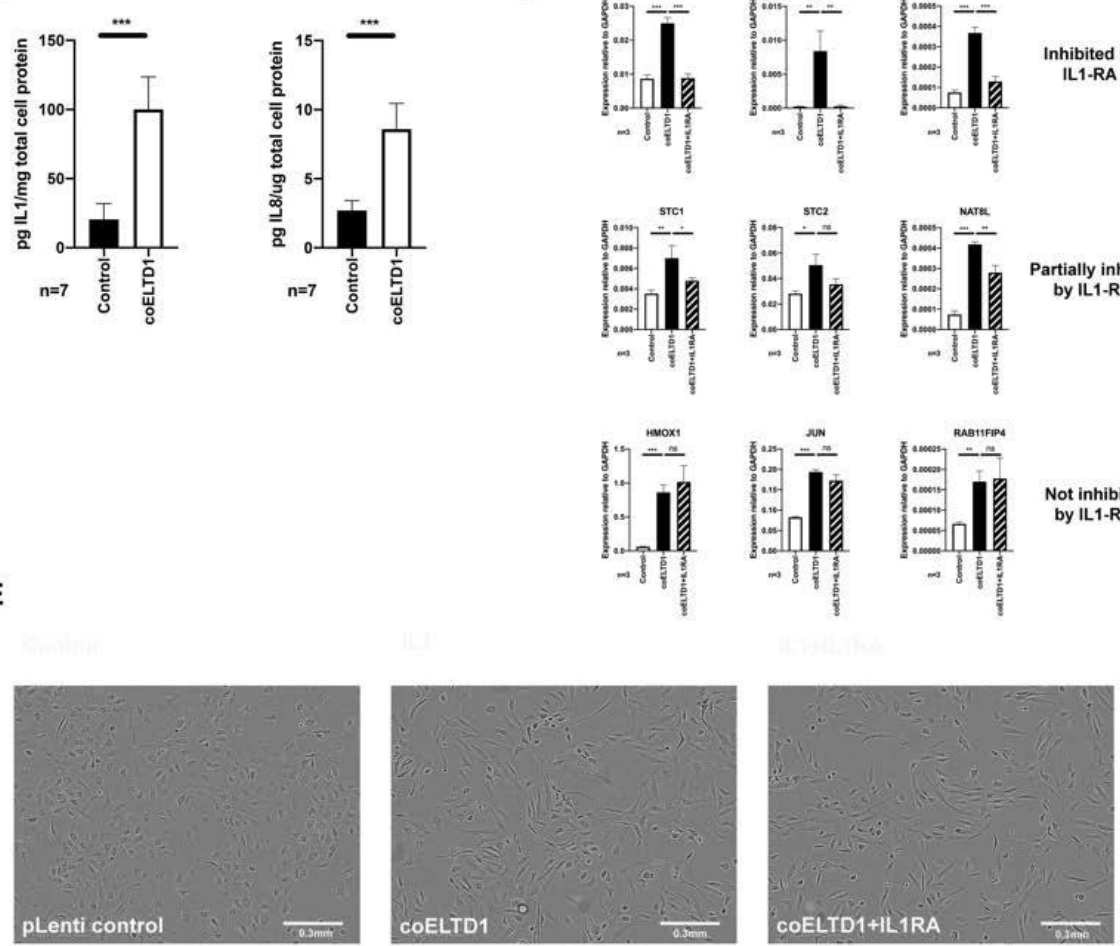

Figure 5: Pro-angiogenic secreted factors are released by coELTD1 expressing cells, including IL1 but IL1 is not responsible for coELTD1 induced EndMT (A) ProteomeProfiler ${ }^{\mathrm{TM}}$ Angiogenesis Array (R\&D Systems) using supernatant collected from control and coELTD1 HUVEC collected at 120hrs. (B) Quantification of the Angiogenesis array and comparison with RNA expression level. (C) Quantification of IL1 and IL8 secretion at $120 \mathrm{hrs}$ using ELISA. (D) Expression of IL1 target genes upon IL1 treatment +/- IL1-receptor antagonist. (E) Visualization of EndMT after IL1 treatment or coELTD1 expression +/- IL1receptor antagonist. Images were taken using the IncuCyte ${ }^{\circledR}$ live cell analysis system (Sartorius) at x10 magnification.
B

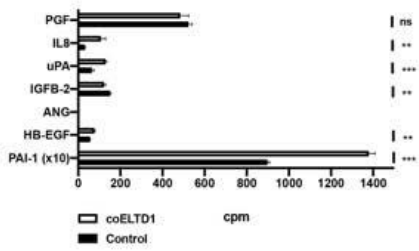

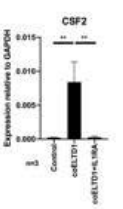

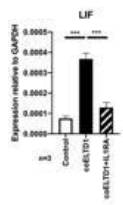

Inhibited by IL1-RA
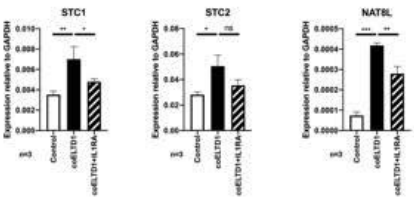

artially inhibited by IL1-RA

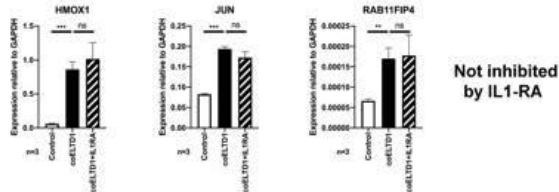




\subsection{In vivo effects of ELTD1 expression.}

HUVEC were infected with coELTD1 expressing or control lentivirus and 48hrs later they were injected into mice in Matrigel $^{\mathrm{TM}}$ to visualise the effects on angiogenesis. coELTD1 expression was confirmed by QPCR along with the expression of genes which were identified during RNAseq analysis (Figure 6A). Six days later the plugs were harvested and increased blood vessel formation was visualised in coELTD1 plugs. Quantification of the number of blood vessels was estimated indirectly by measuring haemoglobin levels in the plugs (Figure 6B). 
A

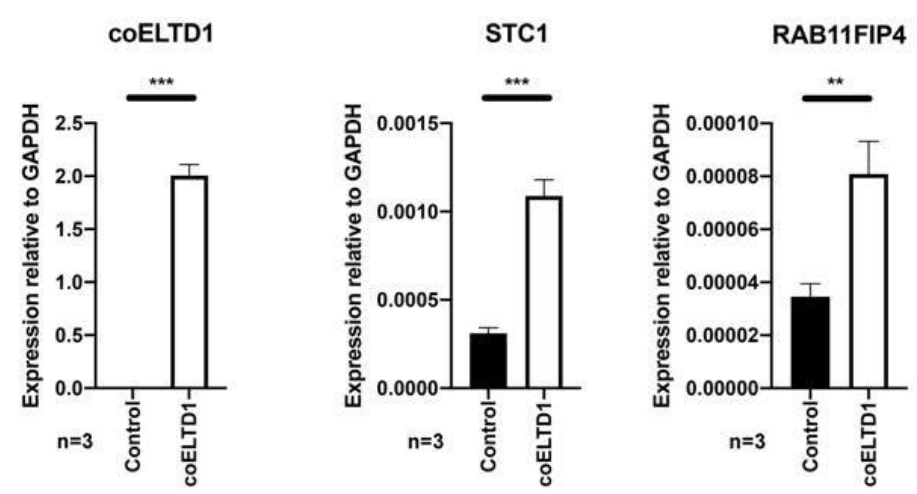

B

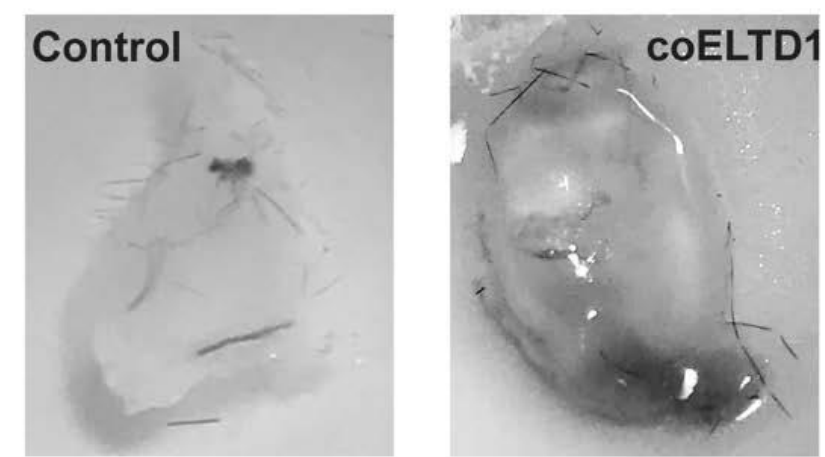

Day 6

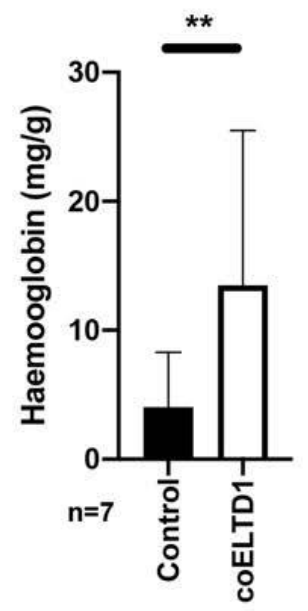

Figure 6: HUVEC expressing coELTD1 increase angiogenesis in vivo. HUVEC were infected with control or coELTD1 lentivirus and embedded in Matrigel ${ }^{\mathrm{TM}}$ at $48 \mathrm{hrs}$. (A) Confirmation of ELTD1 expression was done by QPCR along with genes that were shown to be up-regulated at $48 \mathrm{hrs}$ by RNA-Seq. (B) Matrigel ${ }^{\mathrm{TM}}$ plugs were harvested and photographed before extraction and haemoglobin quantification at 6 days post injection. 


\section{Discussion}

There are three types of EMT depending on its role; Type I is involved in embryogenesis and organ development, Type II occurs during wound healing and is associated with inflammation and fibrosis and Type III is involved in malignancy and metastasis[20]. Endothelial-mesenchymal transition (EndMT) occurs during heart development[21] and Eltd1 and Gpr116 have been reported to function together to regulate this process, with loss of these two proteins in mice leading to malformation of the aortic arch as well the development of a thrombotic microangiopathy[22]. We have also previously shown that eltd 1 is important in blood vessel development in zebrafish with eltd1 silencing causing severe vascular defects[8].

EndMT has also been described in Type II EMT and results in loss of endothelial cell-cell junctions and a decreased expression of endothelial markers such as CD31 and CD34[19]. After vessel damage there are three phases of the healing process; the inflammatory phase, the proliferation phase and the remodelling phase[23]. Inflammatory cytokines released during these processes attract endothelial cells, where they engage in angiogenesis, repair vessels and deliver oxygen and nutrients to the healing wound. They can also transform into myofibroblasts via EndMT[24] but their role in vessel repair remains unclear. EndMT was first described during embryonic heart development via TGF- $\beta$ signalling[25]. In a porcine model, damage to the coronary artery resulted in the formation of vascular myofibroblasts.

Like fibroblast derived myofibroblasts, these non-muscle cells express $\alpha \mathrm{SMA}$ and deposit collagen[26]. As the vessels are normally covered in smooth actin containing muscle cells, the myofibroblasts derived from endothelial cells could easily be overlooked and their role in vessel repair dismissed. Eltd1 has been implicated in cardiac hypertrophy, in mouse knockout models[27]. Lack of Eltd1 resulted in faulty cardiomyocytic remodelling produced by the cardiac pressure overload and a rise in myocardial fibrosis. Myofibroblasts not only express $\alpha \mathrm{SMA}$, they also have mature focal adhesions, form stress fibres and secrete ECM[28]. ELTD1-expressing cells possess all of these features and GSEA analysis of the RNA-Seq further confirms this phenotype with a number of pathways upregulated that are characteristic of myofibroblasts, such as ECM organisation and integrin interactions. As well as secreting collagen, they have a 14fold increase in RNA expression of laminin $\beta 4$ (LAMB4) at 48hrs post infection. This and other myofibroblast derived ECM proteins may be involved in adhering ELTD1 to culture dish surfaces and its resulting deposition in cell tracks. Similar fibroblast derived tracks are thought to be involved in cancer invasion with tumour cells migrating behind invasive stromal fibroblasts[29].

Myofibroblasts exert contractile force in wounds[24] which has been reported to involve $\alpha$ SMA[30]. However wounds can still heal in SMA knock-out mice therefore other proteins may be involved[31]. RNA-Seq data showed increased expression of Titin (TTN) at 48 and 120hrs. TTN is expressed in striated muscle and it provides tension in myofibrils as well as having sensing and signalling functions[32]. Expression of this protein may play an important role in endothelial derived myofibroblast function.

The GSEA also revealed a reduction in cell cycle and DNA replication which explains the reduction in proliferation seen in ELTD1 expressing cells. Myofibroblasts are only transiently present in acute wounds where they are removed by apoptosis or senescence, therefore a reduction in growth would be expected. When they persist they can cause scarring, organ fibrosis and excessive ECM deposition in cancer[33].

EndMT has been reported in a variety of pathologic settings including cancer [34], chronic pulmonary hypotension [35], hypertrophic cardiomyopathy [36] and cardiac fibrosis [25,34]. Tumours have been described as "a wound that never 
heals" and there are many similarities between the development of tumour stroma and the wound healing process [37]. The vast majority of fibroblasts in breast cancer have an activated phenotype [38] with a similar spindle-shaped morphology to myofibroblasts [39]. These have been termed cancer-associated fibroblasts (CAFs) and in certain tumours $40 \%$ have been reported to derive from endothelial cells [34]. CAFs secrete various cytokines, chemokines, growth factors and MMPs to degrade the ECM proteins and contribute to tumour proliferation, invasion, metastasis and angiogenesis [40].

The pro-angiogenic effects of coELTD1 expressing cells were confirmed in vivo using a Matrigel ${ }^{\mathrm{TM}}$ plug assay. The angiogenesis array revealed an increase in a number of pro-angiogenic factors that may be involved in this effect such as HB-EGF[41], PGF [42] and uPA[43]. PAI-1, the inhibitor of uPA was decreased in the supernatant as was IGFBP-2. IGFB-2 is cleaved by PAPPA to release the pro-angiogenic factor IGF-1[44]. PAPPA RNA expression was increased over 2-fold at 48 and 120hrs and may be responsible for the decrease in IGFB-2 levels. RNA-Seq of ELTD1 expressing cells revealed a significant increase in MMP1 and MMP10 at both $48 \mathrm{hrs}$ and $120 \mathrm{hrs}$, both of these proteases are present in cardiac myofibroblasts[45]. VEGFA RNA expression was increased 2 fold at 48hrs, but the main factors released by coELTD1-expressing cells are involved in the immune response. CXCL8 had the largest increase at RNA level (8.9 fold at $48 \mathrm{hrs}$ and 3.5 fold at $120 \mathrm{hrs}$ ) with a 3 -fold increase in secretion as measured by ELISA and angiogenesis array. CXCL8 released from endothelial cells attracts neutrophils to the site of injury but it has also been implicated in fibrosis, angiogenesis and tumorigenesis[46].

IL1 $\alpha$ has the next highest increase in RNA expression (5.3 fold at 48hrs and 2.5 fold at 120hrs) and a 5-fold increase in secretion measured by ELISA. IL1 is not only involved in the immune response, it is also pro-angiogenic and can help drive tumour growth and invasiveness[47]. Although IL1 $\alpha$ is released by ELTD1 expressing cells and can induce EndMT it was not responsible for the EndMT induced by coELTD1. IL1 is known to engage in cross talk with proangiogenic molecules such as VEGF, with the mRNA expression profile of VEGF and IL1 treated HUVEC sharing 63\% homology[48, 49]. This may be another example of such cross talk as many of the gene expression changes seen in coELTD1 cells are seen in IL1 treated cells[50]. Other chemokines that were significantly increased at the RNA level are CXCL1, CXCL3 and CXCL5. These are all pro-angiogenic and have increased expression in different tumour types[51].

A number of other genes were upregulated at 48 and 120hrs. Three of these were in the top 10 most highly expressed at 48hrs; STC1, NAT8L and OLAH. Stanniocalcin-1 is a secreted glycoprotein hormone that has many functions including calcium homeostasis[52]. It promotes wound healing and reepithelization in damaged tissues, inhibits vessel leakage and regulates macrophage functions[53]. It is expressed in CAFs and has been implicated triple negative breast cancer metastasis[54] and pulmonary fibrosis[53]. NAT8L and OLAH have both been implicated in lipid metabolism[55, 56], lipid transport and homeostasis pathways were also upregulated in the GSEA analysis of ELTD1 expressing cells suggesting that this type of energy metabolism is important in endothelial myofibroblast formation and function.

The data presented in this paper show that ELTD1 induces a Type II EndMT. As an adhesion GPCR it has a large ECD that is thought to be involved in cell-cell/cell-matrix adhesion. In the case of ELTD1, this domain may be important in sensing vessel integrity with vessel damage or permeability triggering activation and consequent EndMT. Activation of the receptor may help repair the leaky vessels such as those found in tumours allowing better perfusion and drug delivery. IL1 secretion form several sources in the tumour microenvironment may be responsible for the upregulation reported in tumour vessels. We have previously shown that ELTD1 levels are increased in the tumour vasculature sand this correlates with a good prognosis[8]. Angiogenesis and inflammation are both hallmarks of cancer and are 
interdependent processes than can drive tumorigenesis[57]. ELTD1 is involved in both of these pathways and is also of interest as a driver of myofibroblast formation which is being specifically targeted for fibrosis and cancer[58], ELTD1 is therefore an attractive therapeutic target for a number of pathologic conditions.

\section{Materials and Methods}

\section{Cell Culture and Reagents}

Human umbilical cord endothelial cells (HUVEC) and human microvascular cells (HMEC-1) were purchased from Lonza and cultured in their EGM2 and EGM2-MV media respectively. IL8 and IL1a (R\&D Systems) were added to cells at $10 \mathrm{ng} / \mathrm{ml}$. IL1-receptor antagonist (Sigma) was added at $1 \mu \mathrm{g} / \mathrm{ml}$. The endogenous sequence of ELTD1 is poorly expressed therefore the cDNA was codon optimised using the JCat bioinformatics tool (http://www.jcat.de/) without altering the amino acid coding sequence. Codon optimised ELTD1 (coELTD1) and HA-tagged coELTD1 were cloned into pLenti6.2V5DEST (ThermoFisher) and the vector alone was used as a control. Virus was produced in 293T and concentrated by ultracentrifugation using standard techniques. The viruses were titred using blasticidin resistance and endothelial cells infected at MOI 5 for all experiments.

\section{Cell matrix adhesion assay}

HMEC-1 cells were seeded at $1 \times 10^{4}$ cells per well into the Millicoat ${ }^{\mathrm{TM}}$ ECM Screening Kit (MERCK) and the assay performed according to the manufacturer's instructions.

\section{Cell-cell adhesion assay}

HMEC-1 were seeded at $1.6 \times 10^{6}$ cells into a $10 \mathrm{~cm}$ dish and 50000 cells into a 96 well plate and left to adhere. The next day, $2 \mu \mathrm{M}$ Calcein AM (ThermoFisher) was added to the cells in the $10 \mathrm{~cm}$ dish and incubated for $1 \mathrm{hr}$ at $37^{\circ} \mathrm{C}$. The cells were harvested in PBS+4mM EDTA and washed in PBS. After counting, the cells were resuspended at 2.5x105/ml and $200 \mu \mathrm{l}$ added to the cells in the 96 -well plate. $200 \mu \mathrm{l}$ of the cell suspension was lysed in lysis buffer (20mM Tris pH 7.5, $150 \mathrm{mM} \mathrm{NaCl}, 1 \mathrm{mM}$ EGTA, 1mM EDTA, 1\% Triton X-100) to obtain a total fluorescence reading. After $1 \mathrm{hr}$ the plate was washed gently with warm PBS and cells were lysed in $200 \mu \mathrm{l}$ of buffer. The fluorescence was measured using a FLUOstar optima microplate reader (BMG Labtech) and expressed as a percentage of total fluorescence.

\section{Migration assay}

Migration was assessed using the IncuCyte ${ }^{\circledR}$ live cell analysis system (Sartorius). HUVEC were grown to confluence in a 24-well ImageLock plate and a scratch wound was made using the IncuCyte® wound maker (Sartorius). Images were collected every hour until the wound had closed and the images were analysed using Fiji.

\section{Proliferation assay}

HUVEC proliferation was assessed over a 72 hour time period using the CYQUANT ${ }^{\mathrm{TM}}$ cell proliferation assay (ThermoFisher) according to manufacturer's instructions.

\section{Hanging drop endothelial sprouting assay}




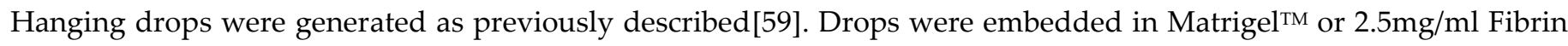
(Sigma) and images acquired every 24hrs using an AMG Evos XL Core digital microscope (Fisher Scientific). The sprouting area was quantified using Fiji.

\section{Tube formation assay}

HUVEC s were plated on top of $200 \mu \mathrm{l}$ of Matrigel ${ }^{\mathrm{TM}}$ at $5 \times 10^{4}$ cells/well in a 24 -well plate (BD Biosciences). Images were collected for 24 hours using the IncuCyte ${ }^{\circledR}$ live cell analysis system (Sartorius) and tube formation was analysed by counting the number of complete polygons.

\section{QPCR protocol}

RNA was extracted using TRI Reagent ${ }^{\circledR}$ (Sigma) according to manufacturer's instructions and reverse transcription was performed using the High Capacity cDNA Archive Kit (Applied Biosystems). Q-PCR reactions were set up using SensiMix ${ }^{\mathrm{TM}}$ SYBR (Bioline) with $20 \mathrm{ng}$ of cDNA and $0.3 \mu \mathrm{M}$ of each oligonucleotide The QPCRs were run in a RotorGene $\mathrm{Q}$ (QIAGEN) The cycling conditions used were: $95^{\circ} \mathrm{C}$ for $10 \mathrm{~min}$ followed by 40 cycles of $95{ }^{\circ} \mathrm{C}$ for $15 \mathrm{~s}$ and $60{ }^{\circ} \mathrm{C}$ for 60 s. A list of primers used are supplied in Table S1.

\section{Western Blotting}

Proteins were separated using SDS-PAGE using standard techniques. Antibodies were purchased from the following companies: ELTD1 (Sigma, CL4164); $\beta$-actin conjugated to HRP (Sigma), HA-Tag (Cell Signaling, 6E2). Secondary antibodies were purchased from DAKO.

\section{Immunohistochemistry (IHC) and Immunocytochemistry (ICC)}

Confocal microscopy was performed using a Zeiss LSM 880 Confocal Microscope or a Zeiss Observer spinning disc confocal microscope using standard protocols. Hoescht 33342 (ThermoFisher) was used to stain nuclei. Antibodies used: ELTD1 ('in house' mouse mAb raised to the extracellular EGF domains, clone name 97.1); $\alpha$ SMA (Sigma, 1A4); Alexa Fluor ${ }^{\circledR} 568$ Phalloidin (ThermoFisher), Alexa Fluor ${ }^{\circledR} 488$ HA-Tag (Cell Signaling); VE-Cadherin (ThermoFisher, BV13), Paxillin (Abcam, Y113).

\section{Collagen assay}

Collagen detection in cell culture media was assessed using Sirius Red collagen detection kit (Chondrex, cat. \# 9062) according to the manufacturer instruction without prior precipitation. Briefly, samples were mixed with the Sirius Red solution at 1:1 ratio, vortexed and incubated for 1 hour at room temperature. After centrifugation at 10,000 rpm for 3 minutes, the pellet was washed with the washing solution and centrifuged again at 10,000 rpm for 3 minutes. The resulting pellet was dissolved using extraction buffer, vortexed and transferred to a 96-well plate for a subsequent measurement of the OD at $540 \mathrm{~nm}$. Media and empty wells alone served as a negative control to exclude any nonspecific signal. The values were normalized to the respective cellular protein content.

\section{ELISA}

Cell culture media was harvested from HUVEC that had undergone EndMT for 48 hrs. IL1 $\alpha$ and IL8 ELISAs were carried out as per manufacturer's instructions (R\&D Systems)

\section{Angiogenesis array}


Cell culture media was harvested from HUVEC that had undergone EndMT for 48hrs. Total cell protein was estimated and the volume of media was adjusted to represent the same amount of protein per condition. The ProteomeProfilerTM Angiogenesis Array (R\&D Systems) was carried out according to manufacturer's instructions.

\section{RNA-Seq}

Purification of mRNA, generation of double stranded cDNA and library construction were performed using NEBNext Poly(A) mRNA Magnetic Isolation Module (E7490) and NEBNext Ultra II Directional RNA Library Prep Kit from Illumina (E7760L). Sequencing was performed on an Illumina NovaSeq6000 as 150bp paired end (PolyA RNA-seq). This generated 72 to 90.6 million reads per sample with FastQC used to evaluate the library quality. Paired-end reads (151 base pair long) were aligned to the human reference genome GRCh38, using STAR 2.5.1b[60] with quantMode GeneCounts and twopassMode basic alignment settings. Details of RNA-Seq analysis can be found in the Supplementary methods.

\section{In vivo Matrigel ${ }^{\mathrm{TM}}$ plug assay.}

All procedures were ethically approved by the UK Home Office on 1/8/2016, number 30/3197. 400 $\mu$ l of Matrigel ${ }^{\mathrm{TM}}$

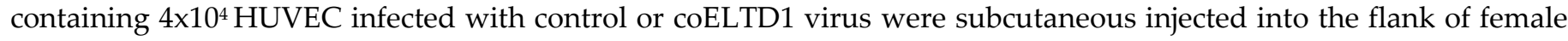
wild-type B57BL.6 mice (aged 5-6weeks; Charles River). Matrigel ${ }^{\mathrm{TM}}$ was removed at day 6 then weighed and photographed. Half of the plug was homogenized in $0.1 \%$ Brij-35 lysis buffer and the haemoglobin levels were measured using Drabkin's reagent as per manufacturer's instructions (Sigma).

\section{Statistical analysis}

Prism 8 (Graphpad Software) was used to analyse the results. All data are represented as mean +/- standard deviation (SD). Student's $t$-test was used to compare two unpaired groups. Significance is denoted as: ${ }^{*} p \leq 0.05,{ }^{* *} p \leq 0.01,{ }^{* * *} p \leq$ 0.001

Supplementary Materials: The following are available online at www.mdpi.com/xxx/s1, Figure S1: coELTD1 expression in HMEC1 and HUVEC results in reduced migration and cell-cell adhesion, Figure S2: HA and FLAG tagging of coELTD1. Figure S3: Increased expression and HA-tagging does not mislocalise ELTD1, Figure S4: RNA-Seq validation, Figure S5: IL1 induces EndMT and ELTD1 expression. Table S1: QPCR primer sequences. Table S2: RNA Expression changes at 48hrs, Table S3: RNA Expression changes at 120hrs, Table S4: Differentially expressed genes at both 48 and 120hrs. Video S1: Control, Video S2: ELTD1, Video S3 HA-tagged coELTD1

Author Contributions: Conceptualization, methodology, investigation, formal analysis, writing original draft, HS. RNA-Seq formal analysis, J.A., S.H. Methodology, investigation and analysis, E.B.,.LM.,SR. Investigation, K.H.A, D.W., S.L. Conceptualization, resources, writing review and editing, A.L.H, A.H.B. All authors have read and agreed to the published version of the manuscript.

Funding: This work was funded by Cancer Research UK (Project no. C602/A18974). J.A. and S.H. would like to thank Breast Cancer Now's funding as part of Programme Funding to the Breast Cancer Now Toby Robins Research Centre.

Institutional Review Board Statement: All animal procedures were carried out in accordance with Home Office licence 30/3197. Data Availability Statement: RNA-Seq data will be publicly available through EBI ENA repository under accession number: PRJEB36900 
Acknowledgments: The authors thank the Oxford Genomics Centre at the Wellcome Centre for Human Genetics (funded by Wellcome Trust grant reference 203141/Z/16/Z) for the generation and initial processing of sequencing data. They thank Christoffer Lagerholm, the facility manager of the Wolfson Imaging Centre, Oxford, for his assistance in confocal microscopy and data analysis.

Conflicts of Interest: The authors declare no conflict of interest

\section{References}

1. Nechiporuk, T.; Urness, L. D.; Keating, M. T., ETL, a novel seven-transmembrane receptor that is developmentally regulated in the heart. ETL is a member of the secretin family and belongs to the epidermal growth factor-seven-transmembrane subfamily. J Biol Chem 2001, 276, (6), 4150-7.

2. Yona, S.; Lin, H. H.; Siu, W. O.; Gordon, S.; Stacey, M., Adhesion-GPCRs: emerging roles for novel receptors. Trends Biochem Sci 2008, 33, (10), 491-500.

3. Arac, D.; Boucard, A. A.; Bolliger, M. F.; Nguyen, J.; Soltis, S. M.; Sudhof, T. C.; Brunger, A. T., A novel evolutionarily conserved domain of cell-adhesion GPCRs mediates autoproteolysis. EMBO J 2012, 31, (6), 1364-78.

4. Cullen, M.; Elzarrad, M. K.; Seaman, S.; Zudaire, E.; Stevens, J.; Yang, M. Y.; Li, X.; Chaudhary, A.; Xu, L.; Hilton, M. B.; Logsdon, D.; Hsiao, E.; Stein, E. V.; Cuttitta, F.; Haines, D. C.; Nagashima, K.; Tessarollo, L.; St Croix, B., GPR124, an orphan $\mathrm{G}$ protein-coupled receptor, is required for CNS-specific vascularization and establishment of the blood-brain barrier. Proc Natl Acad Sci U S A 2011, 108, (14), 5759-64.

5. Wang, T.; Ward, Y.; Tian, L.; Lake, R.; Guedez, L.; Stetler-Stevenson, W. G.; Kelly, K., CD97, an adhesion receptor on inflammatory cells, stimulates angiogenesis through binding integrin counterreceptors on endothelial cells. Blood 2005, 105, (7), 2836-44.

6. Niaudet, C.; Hofmann, J. J.; Mae, M. A.; Jung, B.; Gaengel, K.; Vanlandewijck, M.; Ekvarn, E.; Salvado, M. D.; Mehlem, A.; Al Sayegh, S.; He, L.; Lebouvier, T.; Castro-Freire, M.; Katayama, K.; Hultenby, K.; Moessinger, C.; Tannenberg, P.; Cunha, S.; Pietras, K.; Lavina, B.; Hong, J.; Berg, T.; Betsholtz, C., Gpr116 Receptor Regulates Distinctive Functions in Pneumocytes and Vascular Endothelium. PLoS One 2015, 10, (9), e0137949.

7. Wallgard, E.; Larsson, E.; He, L.; Hellstrom, M.; Armulik, A.; Nisancioglu, M. H.; Genove, G.; Lindahl, P.; Betsholtz, C., Identification of a core set of 58 gene transcripts with broad and specific expression in the microvasculature. Arterioscler Thromb Vasc Biol 2008, 28, (8), 1469-76.

8. $\quad$ Masiero, M.; Simoes, F. C.; Han, H. D.; Snell, C.; Peterkin, T.; Bridges, E.; Mangala, L. S.; Wu, S. Y.; Pradeep, S.; Li, D.; Han, C.; Dalton, H.; Lopez-Berestein, G.; Tuynman, J. B.; Mortensen, N.; Li, J. L.; Patient, R.; Sood, A. K.; Banham, A. H.; Harris, A. L.; Buffa, F. M., A core human primary tumor angiogenesis signature identifies the endothelial orphan receptor ELTD1 as a key regulator of angiogenesis. Cancer Cell 2013, 24, (2), 229-41.

9. Towner, R. A.; Jensen, R. L.; Colman, H.; Vaillant, B.; Smith, N.; Casteel, R.; Saunders, D.; Gillespie, D. L.; Silasi-Mansat, R.; Lupu, F.; Giles, C. B.; Wren, J. D., ELTD1, a potential new biomarker for gliomas. Neurosurgery 2013, 72, (1), 77-90; discussion 91.

10. Ziegler, J.; Pody, R.; Coutinho de Souza, P.; Evans, B.; Saunders, D.; Smith, N.; Mallory, S.; Njoku, C.; Dong, Y.; Chen, H.; Dong, J.; Lerner, M.; Mian, O.; Tummala, S.; Battiste, J.; Fung, K. M.; Wren, J. D.; Towner, R. A., ELTD1, an effective antiangiogenic target for gliomas: preclinical assessment in mouse GL261 and human G55 xenograft glioma models. Neuro Oncol 2017, 19, (2), 175-185.

11. Simundza, J.; Cowin, P., Adhesion G-protein-coupled receptors: elusive hybrids come of age. Cell Commun Adhes 2013, 20, (6), 213-26.

12. Gupte, J.; Swaminath, G.; Danao, J.; Tian, H.; Li, Y.; Wu, X., Signaling property study of adhesion G-protein-coupled receptors. FEBS Lett 2012, 586, (8), 1214-9. 
13. Bond, R. A.; Ijzerman, A. P., Recent developments in constitutive receptor activity and inverse agonism, and their potential for GPCR drug discovery. Trends Pharmacol Sci 2006, 27, (2), 92-6.

14. Kalluri, R.; Weinberg, R. A., The basics of epithelial-mesenchymal transition. J Clin Invest 2009, 119, (6), 1420-8.

15. Van De Water, L.; Varney, S.; Tomasek, J. J., Mechanoregulation of the Myofibroblast in Wound Contraction, Scarring, and Fibrosis: Opportunities for New Therapeutic Intervention. Adv Wound Care (New Rochelle) 2013, 2, (4), $122-141$.

16. Kirfel, G.; Rigort, A.; Borm, B.; Herzog, V., Cell migration: mechanisms of rear detachment and the formation of migration tracks. Eur J Cell Biol 2004, 83, (11-12), 717-24.

17. Klingberg, F.; Hinz, B.; White, E. S., The myofibroblast matrix: implications for tissue repair and fibrosis. J Pathol 2013, 229, (2), 298-309.

18. Lamouille, S.; Xu, J.; Derynck, R., Molecular mechanisms of epithelial-mesenchymal transition. Nat Rev Mol Cell Biol 2014, $15,(3), 178-96$.

19. Cho, J. G.; Lee, A.; Chang, W.; Lee, M. S.; Kim, J., Endothelial to Mesenchymal Transition Represents a Key Link in the Interaction between Inflammation and Endothelial Dysfunction. Front Immunol 2018, 9, 294.

20. Kovacic, J. C.; Mercader, N.; Torres, M.; Boehm, M.; Fuster, V., Epithelial-to-mesenchymal and endothelial-to-mesenchymal transition: from cardiovascular development to disease. Circulation 2012, 125, (14), 1795-808.

21. Kovacic, J. C.; Dimmeler, S.; Harvey, R. P.; Finkel, T.; Aikawa, E.; Krenning, G.; Baker, A. H., Endothelial to Mesenchymal Transition in Cardiovascular Disease: JACC State-of-the-Art Review. J Am Coll Cardiol 2019, 73, (2), 190-209.

Lu, S.; Liu, S.; Wietelmann, A.; Kojonazarov, B.; Atzberger, A.; Tang, C.; Schermuly, R. T.; Grone, H. J.; Offermanns, S., Developmental vascular remodeling defects and postnatal kidney failure in mice lacking Gpr116 (Adgrf5) and Eltd1 (Adgrl4). PLoS One 2017, 12, (8), e0183166.

Gurtner, G. C.; Werner, S.; Barrandon, Y.; Longaker, M. T., Wound repair and regeneration. Nature 2008, 453, (7193), $314-21$.

24. Micallef, L.; Vedrenne, N.; Billet, F.; Coulomb, B.; Darby, I. A.; Desmouliere, A., The myofibroblast, multiple origins for major roles in normal and pathological tissue repair. Fibrogenesis Tissue Repair 2012, 5, (Suppl 1), S5.

25. Zeisberg, E. M.; Tarnavski, O.; Zeisberg, M.; Dorfman, A. L.; McMullen, J. R.; Gustafsson, E.; Chandraker, A.; Yuan, X.; Pu, W. T.; Roberts, A. B.; Neilson, E. G.; Sayegh, M. H.; Izumo, S.; Kalluri, R., Endothelial-to-mesenchymal transition contributes to cardiac fibrosis. Nat Med 2007, 13, (8), 952-61.

26. Zalewski, A.; Shi, Y., Vascular myofibroblasts. Lessons from coronary repair and remodeling. Arterioscler Thromb Vasc Biol $1997,17,(3), 417-22$.

27. Xiao, J.; Jiang, H.; Zhang, R.; Fan, G.; Zhang, Y.; Jiang, D.; Li, H., Augmented cardiac hypertrophy in response to pressure overload in mice lacking ELTD1. PLoS One 2012, 7, (5), e35779.

28. Goffin, J. M.; Pittet, P.; Csucs, G.; Lussi, J. W.; Meister, J. J.; Hinz, B., Focal adhesion size controls tension-dependent recruitment of alpha-smooth muscle actin to stress fibers. J Cell Biol 2006, 172, (2), 259-68.

29. Gaggioli, C.; Hooper, S.; Hidalgo-Carcedo, C.; Grosse, R.; Marshall, J. F.; Harrington, K.; Sahai, E., Fibroblast-led collective invasion of carcinoma cells with differing roles for RhoGTPases in leading and following cells. Nat Cell Biol 2007, 9, (12), 1392-400.

30. Hinz, B.; Celetta, G.; Tomasek, J. J.; Gabbiani, G.; Chaponnier, C., Alpha-smooth muscle actin expression upregulates fibroblast contractile activity. Mol Biol Cell 2001, 12, (9), 2730-41.

31. Tomasek, J. J.; Gabbiani, G.; Hinz, B.; Chaponnier, C.; Brown, R. A., Myofibroblasts and mechano-regulation of connective tissue remodelling. Nat Rev Mol Cell Biol 2002, 3, (5), 349-63.

LeWinter, M. M.; Wu, Y.; Labeit, S.; Granzier, H., Cardiac titin: structure, functions and role in disease. Clin Chim Acta 2007, $375,(1-2), 1-9$.

33. Cox, T. R.; Erler, J. T., Molecular pathways: connecting fibrosis and solid tumor metastasis. Clin Cancer Res 2014, 20, (14), 3637-43. 
34. Zeisberg, E. M.; Potenta, S.; Xie, L.; Zeisberg, M.; Kalluri, R., Discovery of endothelial to mesenchymal transition as a source for carcinoma-associated fibroblasts. Cancer Res 2007, 67, (21), 10123-8.

35. Arciniegas, E.; Frid, M. G.; Douglas, I. S.; Stenmark, K. R., Perspectives on endothelial-to-mesenchymal transition: potential contribution to vascular remodeling in chronic pulmonary hypertension. Am J Physiol Lung Cell Mol Physiol 2007, 293, (1), L1-8.

36. Teekakirikul, P.; Eminaga, S.; Toka, O.; Alcalai, R.; Wang, L.; Wakimoto, H.; Nayor, M.; Konno, T.; Gorham, J. M.; Wolf, C. M.; Kim, J. B.; Schmitt, J. P.; Molkentin, J. D.; Norris, R. A.; Tager, A. M.; Hoffman, S. R.; Markwald, R. R.; Seidman, C. E.; Seidman, J. G., Cardiac fibrosis in mice with hypertrophic cardiomyopathy is mediated by non-myocyte proliferation and requires Tgf-beta. J Clin Invest 2010, 120, (10), 3520-9.

37. Dvorak, H. F., Tumors: wounds that do not heal. Similarities between tumor stroma generation and wound healing. $N$ Engl J Med 1986, 315, (26), 1650-9.

38. Sappino, A. P.; Skalli, O.; Jackson, B.; Schurch, W.; Gabbiani, G., Smooth-muscle differentiation in stromal cells of malignant and non-malignant breast tissues. Int J Cancer 1988, 41, (5), 707-12.

39. De Wever, O.; Demetter, P.; Mareel, M.; Bracke, M., Stromal myofibroblasts are drivers of invasive cancer growth. Int J Cancer 2008, 123, (10), 2229-38.

40. LeBleu, V. S.; Kalluri, R., A peek into cancer-associated fibroblasts: origins, functions and translational impact. Dis Model Mech 2018, 11, (4).

41. Ongusaha, P. P.; Kwak, J. C.; Zwible, A. J.; Macip, S.; Higashiyama, S.; Taniguchi, N.; Fang, L.; Lee, S. W., HB-EGF is a potent inducer of tumor growth and angiogenesis. Cancer Res 2004, 64, (15), 5283-90.

42. Carmeliet, P.; Moons, L.; Luttun, A.; Vincenti, V.; Compernolle, V.; De Mol, M.; Wu, Y.; Bono, F.; Devy, L.; Beck, H.; Scholz, D.; Acker, T.; DiPalma, T.; Dewerchin, M.; Noel, A.; Stalmans, I.; Barra, A.; Blacher, S.; VandenDriessche, T.; Ponten, A.; Eriksson, U.; Plate, K. H.; Foidart, J. M.; Schaper, W.; Charnock-Jones, D. S.; Hicklin, D. J.; Herbert, J. M.; Collen, D.; Persico, M. G., Synergism between vascular endothelial growth factor and placental growth factor contributes to angiogenesis and plasma extravasation in pathological conditions. Nat Med 2001, 7, (5), 575-83.

43. Breuss, J. M.; Uhrin, P., VEGF-initiated angiogenesis and the uPA/uPAR system. Cell Adh Migr 2012, 6, (6), 535-615.

44. Oxvig, C., The role of PAPP-A in the IGF system: location, location, location. J Cell Commun Signal 2015, 9, (2), $177-87$.

45. Turner, N. A.; Warburton, P.; O'Regan, D. J.; Ball, S. G.; Porter, K. E., Modulatory effect of interleukin-1alpha on expression of structural matrix proteins, MMPs and TIMPs in human cardiac myofibroblasts: role of p38 MAP kinase. Matrix Biol 2010, $29,(7), 613-20$.

46. Russo, R. C.; Garcia, C. C.; Teixeira, M. M.; Amaral, F. A., The CXCL8/IL-8 chemokine family and its receptors in inflammatory diseases. Expert Rev Clin Immunol 2014, 10, (5), 593-619.

47. Voronov, E.; Carmi, Y.; Apte, R. N., The role IL-1 in tumor-mediated angiogenesis. Front Physiol $2014,5,114$.

48. Schweighofer, B.; Testori, J.; Sturtzel, C.; Sattler, S.; Mayer, H.; Wagner, O.; Bilban, M.; Hofer, E., The VEGF-induced transcriptional response comprises gene clusters at the crossroad of angiogenesis and inflammation. Thromb Haemost 2009, 102, (3), 544-54.

49. Mohr, T.; Haudek-Prinz, V.; Slany, A.; Grillari, J.; Micksche, M.; Gerner, C., Proteome profiling in IL-1beta and VEGFactivated human umbilical vein endothelial cells delineates the interlink between inflammation and angiogenesis. PLoS One 2017, 12, (6), e0179065.

50. Mayer, H.; Bilban, M.; Kurtev, V.; Gruber, F.; Wagner, O.; Binder, B. R.; de Martin, R., Deciphering regulatory patterns of inflammatory gene expression from interleukin-1-stimulated human endothelial cells. Arterioscler Thromb Vasc Biol 2004, 24, (7), 1192-8.

51. Keeley, E. C.; Mehrad, B.; Strieter, R. M., Chemokines as mediators of tumor angiogenesis and neovascularization. Exp Cell Res 2011, 317, (5), 685-90. 
52. Yoshiko, Y.; Aubin, J. E., Stanniocalcin 1 as a pleiotropic factor in mammals. Peptides 2004, 25, (10), 1663-9.

53. Ohkouchi, S.; Ono, M.; Kobayashi, M.; Hirano, T.; Tojo, Y.; Hisata, S.; Ichinose, M.; Irokawa, T.; Ogawa, H.; Kurosawa, H., Myriad Functions of Stanniocalcin-1 (STC1) Cover Multiple Therapeutic Targets in the Complicated Pathogenesis of Idiopathic Pulmonary Fibrosis (IPF). Clin Med Insights Circ Respir Pulm Med 2015, 9, (Suppl 1), 91-6.

54. Chen, F.; Zhang, Z.; Pu, F., Role of stanniocalcin-1 in breast cancer. Oncol Lett 2019, 18, (4), 3946-3953.

55. Pessentheiner, A. R.; Pelzmann, H. J.; Walenta, E.; Schweiger, M.; Groschner, L. N.; Graier, W. F.; Kolb, D.; Uno, K.; Miyazaki, T.; Nitta, A.; Rieder, D.; Prokesch, A.; Bogner-Strauss, J. G., NAT8L (N-acetyltransferase 8-like) accelerates lipid turnover and increases energy expenditure in brown adipocytes. J Biol Chem 2013, 288, (50), 36040-51.

56. Ritchie, M. K.; Johnson, L. C.; Clodfelter, J. E.; Pemble, C. W. t.; Fulp, B. E.; Furdui, C. M.; Kridel, S. J.; Lowther, W. T., Crystal Structure and Substrate Specificity of Human Thioesterase 2: INSIGHTS INTO THE MOLECULAR BASIS FOR THE MODULATION OF FATTY ACID SYNTHASE. J Biol Chem 2016, 291, (7), 3520-30.

57. Hanahan, D.; Weinberg, R. A., Hallmarks of cancer: the next generation. Cell 2011, 144, (5), 646-74.

58. Yazdani, S.; Bansal, R.; Prakash, J., Drug targeting to myofibroblasts: Implications for fibrosis and cancer. Adv Drug Deliv Rev 2017, 121, 101-116.

59. Oon, C. E.; Bridges, E.; Sheldon, H.; Sainson, R. C. A.; Jubb, A.; Turley, H.; Leek, R.; Buffa, F.; Harris, A. L.; Li, J. L., Role of Delta-like 4 in Jagged1-induced tumour angiogenesis and tumour growth. Oncotarget 2017, 8, (25), 40115-40131.

60. Dobin, A.; Davis, C. A.; Schlesinger, F.; Drenkow, J.; Zaleski, C.; Jha, S.; Batut, P.; Chaisson, M.; Gingeras, T. R., STAR: ultrafast universal RNA-seq aligner. Bioinformatics 2013, 29, (1), 15-21. 